\title{
D-q Equivalent Circuit-based Protection Algorithm for a Doubly-fed Induction Generator in the Time Domain
}

\author{
Yong-Cheol Kang*, Hae-Gweon Kang ${ }^{\dagger}$ and Ji-Hoon Lee*
}

\begin{abstract}
Most modern wind turbines employ a doubly-fed induction generator (DFIG) system due to its many advantages, such as variable speed operation, relatively high efficiency, and small converter size. The DFIG system uses a wound rotor induction machine so that the magnetizing current of the generator can be fed from both the stator and the rotor. We propose a protection algorithm for a DFIG based on a d-q equivalent circuit in the time domain. In the DFIG, the voltages and currents of the rotor side and the stator side are available. The proposed algorithm estimates the instantaneous induced voltages of magnetizing inductance using those voltages and currents from both the stator and the rotor sides. If the difference between the two estimated induced voltages exceeds the threshold, the proposed algorithm detects an internal fault. The performance of the proposed algorithm is verified under various operating and fault conditions using a PSCAD/EMTDC simulator.
\end{abstract}

Keywords: Doubly-fed induction generator, D-q equivalent circuit, Turn-to-turn fault, Protection algorithm

\section{Introduction}

Among the choices in renewable energy, wind energy has been playing an increasingly important role because the cost of electricity from wind power is decreasing, and is nearly the same as that of gasoline [1]. In recent years, wind turbine technology has reached a very reliable and sophisticated level. The growing worldwide market will lead to further improvements, such as larger wind turbines and new system applications (e.g., offshore wind farms) [2].

Wind power using a doubly-fed induction generator (DFIG) is becoming prevalent because of reliability and economic efficiency [3]. The DFIG uses a wound rotor induction machine so that the magnetizing current of the generator can be fed from the rotor as well as the stator. The stator of a DFIG is connected to the grid directly whilst the rotor is connected to the grid through back-toback converters [4], [5]. The construction of a DFIG system is complicated, because output power is controlled by the rotor currents from the converter. However, the converter deals with relatively small power, approximately 10 $25 \%$ of nominal turbine power, so that the size of the converter can be minimized. Thus, the DFIG is a cost-efficient solution for variable speed wind generation.

As the capacity and penetration of wind power increases, a reliable wind turbine protection scheme becomes very important. In particular, for machines which use a converter like a DFIG system, special attention should be paid to a turn-to-turn fault. This is because stator insulation is easy to expose increased thermal and electrical stresses

$\dagger \quad$ Corresponding Author: Dep. of Electrical Engineering, Chonbuk National University, Chonju, 561-756, Korea.

(khgforever@chonbuk.ac.kr)

* Dep. of Electrical Engineering, Chonbuk National University, Chonju, 561-756, Korea. (yckang@chonbuk.ac.kr, reviva19126@chonbuk.ac.kr) Received: February 5, 2010; Accepted: April 5, 2010 resulting from high switching voltages and high-order harmonics of the converter. When a fault occurs in the windings of a generator, the high current in the short circuit may cause a subsequent fault in normal windings. Thus, the windings might be burned due to the increased high thermal stress [6], [7]. In addition, for a single phase fault in the windings, the unbalanced currents and voltages negatively influence the grid. Therefore, a protection scheme for a DFIG should detect the fault as quickly as possible.

Currently, a current differential relay is used as the main protection for generator windings. The relay detects a phase-to-ground fault and a line-to-line fault successfully because the differential current becomes very large. The relay, however, maloperates for a turn-to-turn fault because the magnitude of the differential current is minimal [8], [9].

Research on various monitoring techniques has been reported using different machine variables for the turn-toturn faults of an induction machine. However, these monitoring methods are not protection techniques but online detection techniques of incipient faults to avoid unexpected failure of the machine [10].

This paper proposes a protection algorithm for a DFIG based on a d-q equivalent circuit in the time domain. In the case of a DFIG, the voltages and currents of the rotor side as well as the voltages and currents of the stator side are available. The proposed algorithm estimates the two instantaneous (i.e., converted into the stationary reference frame) induced voltages of magnetizing inductance using the voltages and currents of the rotor and stator side. The two induced voltages are nearly the same for the steady state and the transient state (such as wind speed variation). However, they differ in the case of internal fault. If the difference between the two estimated induced voltages exceeds a threshold, the proposed algorithm detects the fault as an internal fault. The performance of the proposed algorithm 
is verified under various operating and fault conditions using a PSCAD/EMTDC simulator.

\section{Modeling of the DFIG System}

Fig. 1 represents the structure of a DFIG system. The model of a DFIG system consists of blade model, generator model, converter model, controllers, and grid. The wind speed is modeled as constant, and we do not include a shaft model, pitch angle control and converter protection system. We will discuss the modeling of the machine and the converter and control system in detail.

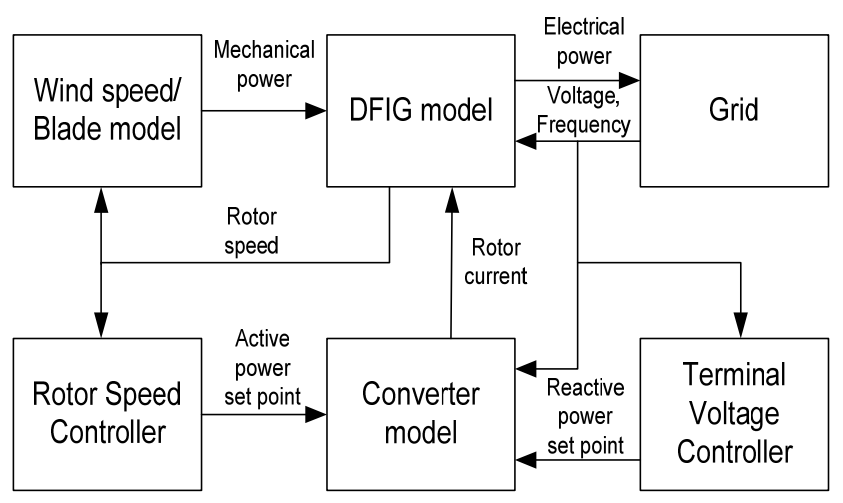

Fig. 1. Structure of a DFIG system.

\subsection{Machine Modeling}

The three-phase modeling of the wound rotor induction generator is as follows. The voltage and linkage flux equations of the stator and the rotor sides of a DFIG are defined by

$$
\begin{gathered}
\mathbf{V}_{a b c s}=r_{s} \mathbf{I}_{a b c s}+\frac{d}{d t} \boldsymbol{\Lambda}_{a b c s} \\
\mathbf{V}_{a b c r}=r_{r} \mathbf{I}_{a b c r}+\frac{d}{d t} \boldsymbol{\Lambda}_{a b c r} \\
\boldsymbol{\Lambda}_{a b c s}=\mathbf{L}_{s} \mathbf{I}_{a b c s}+\mathbf{L}_{s r} \mathbf{I}_{a b c r} \\
\boldsymbol{\Lambda}_{a b c r}=\mathbf{L}_{r} \mathbf{I}_{a b c r}+\left(\mathbf{L}_{s r}\right)^{T} \mathbf{I}_{a b c s}
\end{gathered}
$$

where $\mathbf{V}_{a b c s}$ and $\mathbf{V}_{a b c r}$ represent the voltage matrices ( $\left.3 \times 1\right)$; $\mathbf{I}_{a b c s}$ and $\mathbf{I}_{a b c r}$ represent the current matrices (3 X 1); $\boldsymbol{\Lambda}_{a b c s}$ and $\boldsymbol{\Lambda}_{a b c r}$ represent the linkage flux matrices ( $\left.3 \times 1\right) ; \mathbf{L}_{s}$ and $\mathbf{L}_{r}$ represent the inductance matrices $(3 \times 3)$; and $\mathbf{L}_{s r}$ represents the mutual inductance matrix $(3 \times 3)$. The subscripts $s$ and $r$ represent stator and the rotor, respectively [11]-[13].

To transform the three-phase variables defined in (1)-(4) to the d-q-n axis, we multiply the variables by the transform matrix $\mathbf{T}(\theta)$. $\mathbf{T}(\theta)$ can be divided into the transform matrix of the rotor frame $\mathbf{R}(\theta)$ and the transform matrix of the stationary reference frame $\mathbf{T}(0)$ as follows:

$$
\begin{gathered}
\mathbf{T}(\theta)=\mathbf{R}(\theta) \mathbf{T}(0)=\left[\begin{array}{ccc}
\cos \theta & \sin \theta & 0 \\
-\sin \theta & \cos \theta & 0 \\
0 & 0 & 1
\end{array}\right] \frac{2}{3}\left[\begin{array}{ccc}
1 & -\frac{1}{2} & -\frac{1}{2} \\
0 & \frac{\sqrt{3}}{2} & -\frac{\sqrt{3}}{2} \\
\frac{1}{2} & \frac{1}{2} & \frac{1}{2}
\end{array}\right] \\
\theta=\int_{0}^{t} \omega(\zeta) d \zeta+\theta(0)
\end{gathered}
$$

where $\omega$ is the rotating speed of d-q-n axis. In the stationary reference frame $\omega=0$, and in the synchronously rotating reference frame $\omega=\omega_{e}$.

To realize the d-q equivalent circuit of a DFIG transformed to the stationary reference frame, both the rotor side variables and stator side variables are transformed to the stationary reference frame. The transformed stator voltage can be obtained by multiplying $\mathbf{T}(0)$ by (1), and the transformed stator linkage flux can be obtained from the product of $\mathbf{T}(0)$ and (3). This yields:

$$
\begin{gathered}
v_{d s}^{s}=-r_{s} i_{d s}^{s}+\frac{d}{d t} \lambda_{d s}^{s} \\
v_{q s}^{s}=-r_{s} i_{q s}^{s}+\frac{d}{d t} \lambda_{q s}^{s} \\
\lambda_{d s}^{s}=-L_{l s} i_{d s}^{s}-L_{m}\left(i_{d s}^{s}+i_{d r}^{s}\right) \\
\lambda_{q s}^{s}=-L_{l s} i_{q s}^{s}-L_{m}\left(i_{q s}^{s}+i_{q r}^{s}\right)
\end{gathered}
$$

In addition, the voltage and linkage flux equations of the rotor transformed to the stationary reference frame are calculated as follows. The rotor side variables are converted into the stator side variables considering the winding ratio ( $\mathrm{a}=N_{\mathrm{s}} / N_{\mathrm{r}}$ ), and are then multiplied by $\mathbf{R}\left(\theta_{e}\right)^{-1} \mathbf{T}\left(\theta_{s l}\right)$. This synchronizes the frequency to the rotor side variables which are transformed to the stationary reference frame, where $\theta_{e}$ is the angular position of the synchronously rotating reference frame and $\theta_{s l}$ which can be calculated by $\theta_{e}-$ $\theta_{r}$, is the slip angle. The voltage and linkage flux of the rotor transformed to the stationary reference frame are defined by

$$
\begin{gathered}
v_{d r}^{s}=-a^{2} r_{r} i_{d r}^{s}-\omega_{r} \lambda_{q r}^{s}+\frac{d}{d t} \lambda_{d r}^{s} \\
v_{q r}^{s}=-a^{2} r_{r} i_{q r}^{s}+\omega_{r} \lambda_{d r}^{s}+\frac{d}{d t} \lambda_{q r}^{s} \\
\lambda_{d r}^{s}=-a^{2} L_{l r} i_{d r}^{s}-L_{m}\left(i_{d s}^{s}+i_{d r}^{s}\right) \\
\lambda_{q r}^{s}=-a^{2} L_{l r} i_{q r}^{s}-L_{m}\left(i_{q s}^{s}+i_{q r}^{s}\right)
\end{gathered}
$$

Using these voltage and linkage flux equations transformed to the stationary reference frame, the d-q equivalent circuit of a DFIG transformed to the stationary reference frame can be realized as shown in Fig. 2, where $r_{s}$ and $r_{r}$ represent the winding resistance of the stator and the rotor, respectively. $L_{l s}$ and $L_{l r}$ represent the leakage inductance of the stator and the rotor, respectively, and $\omega_{r}$ represents the angular velocity of the rotor. 


\subsection{Converter Modeling}

The converters linked to the rotor side of a DFIG are divided to a machine side converter and a grid side converter. The two converters are separated through a DC link capacitor.

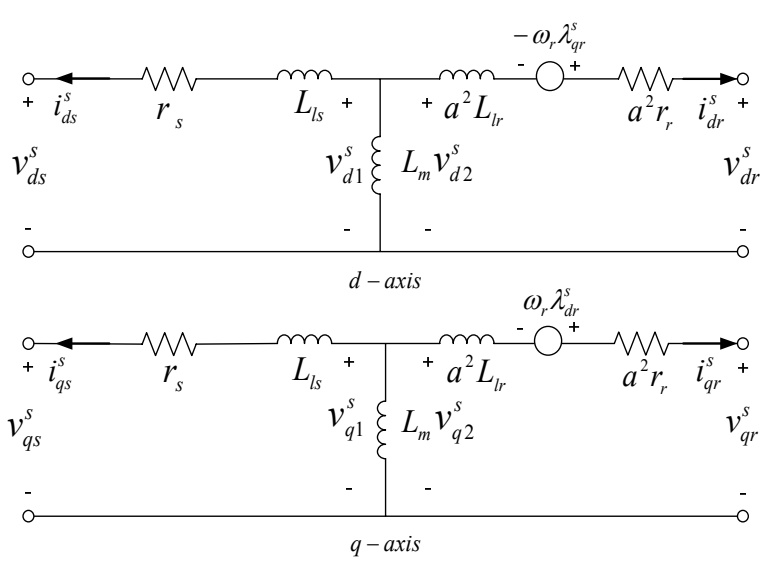

Fig. 2. d-q equivalent circuit of a DFIG transformed into a stationary reference frame follows [5], [14].

The converters control active and reactive power using the d-axis current and q-axis current, and also the voltage of the DC link capacitor can be controlled by the grid side converter.

The machine side converter should calculate the $\theta_{e}$, because it has to control the current transformed to the stationary reference frame. The $\theta_{e}$ can be calculated using the rotor and stator flux. $\theta_{e}$ is defined as

$$
\theta_{e}=\tan ^{-1} \frac{\lambda_{q s}^{s}}{\lambda_{d s}^{s}}
$$

The stator flux is difficult to measure therefore $\lambda_{d s}^{s}$ and $\lambda_{q s}^{s}$ are estimated using the voltage and current equation as

$$
\begin{aligned}
& \lambda_{d s}^{s}=\int\left\{v_{d s}^{s}+r_{s} i_{d s}^{s}\right\} d t \\
& \lambda_{q s}^{s}=\int\left\{v_{q s}^{s}+r_{s} i_{q s}^{s}\right\} d t
\end{aligned}
$$

The control of the q-axis current is used for the active power control. By inserting $\lambda_{q s}^{s}=0$ in (9)

$$
i_{q s}^{s}=-\frac{L_{m}}{L_{s}} i_{q r}^{s}
$$

On the other hand, the control of the d-axis current is used for the reactive power control of stator. First, the equation of reactive power transformed to the stationary reference frame is

$$
Q_{s}=\frac{3}{2}\left(v_{q s}^{s} i_{d s}^{s}-v_{d s}^{s} i_{q s}^{s}\right)
$$

Inserting (8) and (18) in (19) yields

$$
\begin{aligned}
Q_{s} & =\frac{3}{2}\left(v_{q s}^{s} \frac{1}{L_{s}} \lambda_{d s}^{s}-v_{q s}^{s} \frac{L_{m}}{L_{s}} i_{d r}^{s}+v_{d s}^{s} \frac{L_{m}}{L_{s}} i_{q r}^{s}\right) \\
& =\frac{3}{2} \frac{1}{L_{s}}\left(v_{q s}^{s} \lambda_{d s}^{s}-L_{m} v_{q s}^{s} i_{d r}^{s}+L_{m} v_{d s}^{s} i_{q r}^{s}\right)
\end{aligned}
$$

From (20), the d-axis current of the rotor is defined by

$$
i_{d r}^{s}=-\frac{2}{3} \frac{L_{s}}{L_{m}} \frac{1}{v_{q s}^{s}} Q_{s}+\frac{1}{L_{m}} \lambda_{d s}^{s}+\frac{v_{d s}^{s}}{v_{q s}^{s}} i_{q r}^{s}
$$

The voltage control of a DC link capacitor can be performed using both the input active power control and the output active power control of the capacitor. The state equations of a grid side converter transformed to the stationary reference frame are defined by

$$
\begin{aligned}
& e_{d}^{s}=-e_{\max } \sin \omega t \\
& e_{q}^{s}=e_{\max } \cos \omega t
\end{aligned}
$$

We make the $e^{s}{ }_{d}$ to be zero when the grid side converter calculates $\theta_{e}$, therefore the active power of the grid side converter is

$$
P_{G S C}=\frac{3}{2}\left(e_{d}^{s} i_{d}^{s}+e_{q}^{s} i_{q}^{s}\right)=\frac{3}{2} e_{\max } i_{q}^{s}
$$

In (23), the q-axis current is proportional to the active power of the grid side, because the q-axis voltage is constant. Therefore, we can control the DC link voltage through the control of the q-axis current.

\section{D-q Equivalent Circuits based Protection Algorithm for a DFIG in the Time Domain}

This paper proposes a protection algorithm which can detect the internal fault of a DFIG. The algorithm can detect internal faults, including the turn-to-turn fault, which cannot be detected successfully using the current differential relay. Therefore, the proposed algorithm can realize more reliable protection system of a DFIG.

The proposed algorithm estimates the two induced voltages of $L_{\mathrm{m}}$ from the stator side and the rotor side in the time domain, and detects the internal faults by comparing these two induced voltages. The $d-q$ transformation to the stationary reference frame is used to obtain the induced voltages of $L_{m}$ in this paper. These induced voltages, $v_{d 1}^{s}$, $v_{d 2}^{s}, v_{q 1}^{s}$, and $v_{q 2}^{s}$ in Fig. 2 are given by 


$$
\begin{gathered}
v_{d 1}^{s}=v_{d s}^{s}+r_{s} i_{d s}^{s}+L_{l s} \frac{d i_{d s}^{s}}{d t} \\
v_{d 2}^{s}=v_{d r}^{s}+a^{2} r_{r} i_{d r}^{s}-\omega_{r}\left(a^{2} L_{l r} i_{q r}^{s}+L_{m}\left(i_{q s}^{s}+i_{q r}^{s}\right)\right)+a L_{l s} \frac{d i_{d s}^{s}}{d t} \\
v_{q 1}^{s}=v_{q s}^{s}+r_{s} i_{q s}^{s}+L_{l s} \frac{d i_{q s}^{s}}{d t} \\
v_{q 2}^{s}=v_{q r}^{s}+a^{2} r_{r} i_{q r}^{s}+\omega_{r}\left(a^{2} L_{l r} i_{d r}^{s}+L_{m}\left(i_{d s}^{s}+i_{d r}^{s}\right)\right)+a L_{l r} \frac{d i_{q r}^{s}}{d t}
\end{gathered}
$$

For the steady state and the transient state, $v_{d 1}^{s}$ and $v_{q 1}^{s}$ are identical to $v_{d 2}^{s}$ and $v_{q 2}^{s}$, respectively. However, they become different in the case of internal faults. This is because the parameters of the windings are changed when an internal fault occurs. Therefore, the proposed algorithm compares these two induced voltages at any instant to detect the internal fault. The detectors of the d-axis and the qaxis for fault detection are defined by

$$
\begin{aligned}
& \text { D_detector }=\frac{v_{d 2 r m s}^{s}-v_{d 1 r m s}^{s}}{\sqrt{2} V_{d 1 r m s}} \times 100 \% \\
& \mathbf{Q} \_ \text {detector }=\frac{v_{q 2 r m s}^{s}-v_{q 1 r m s}^{s}}{\sqrt{2} V_{q 1 r m s}} \times 100 \%
\end{aligned}
$$

where $V_{d 1 r m s}$ and $V_{\text {qlrms }}$ mean the root mean square values of $v_{d l}^{s}$ and $v_{q l}^{s}$ in the steady state.

The procedure of the proposed algorithm is as follows. At first, the inputs are voltages and currents of the stator and the rotor sides of a DFIG, and $\omega_{r}$. The input voltages and currents are passed through an anti-aliasing low-pass filter and then transformed to the stationary reference frame. Finally, the values of D detector and Q detector are calculated using $v_{d 1}^{s}, v_{d 2}^{s}, v_{q 1}^{s}$, and $v_{q 2}^{s}$ from (24)-(29).

The proposed algorithm detects the internal faults if either $\mid \mathrm{D}$ detector $\mid$ or $\mid \mathrm{Q}$ detector $\mid$ exceeds the threshold. In this paper, we set the threshold as $5 \%$ to prevent a malfunction because of a disturbance in the transient state. However, for the real-time realization of the proposed algorithm, the threshold value may become different depending on the measurement errors and noise. If the value of $\mid \mathrm{D}$ detector $\mid$ or $\mid \mathrm{Q}$ detector| exceeds $5 \%$, the counter is increased by 1 ; otherwise, the counter is decreased by 1 . The counter is used to prevent maloperation due to the noise in the transient state during the fault conditions. The trip signal is activated when the value of the counter becomes 16 .

\section{Case Studies}

To verify the performance of the algorithm, a $3 \mathrm{~kW}$ DFIG-type wind power generation system was modeled by PSCAD/EMTDC as shown in Fig. 3. The voltages and the currents were measured at the terminal of the stator windings and the input-output port of the machine-side converter, respectively.

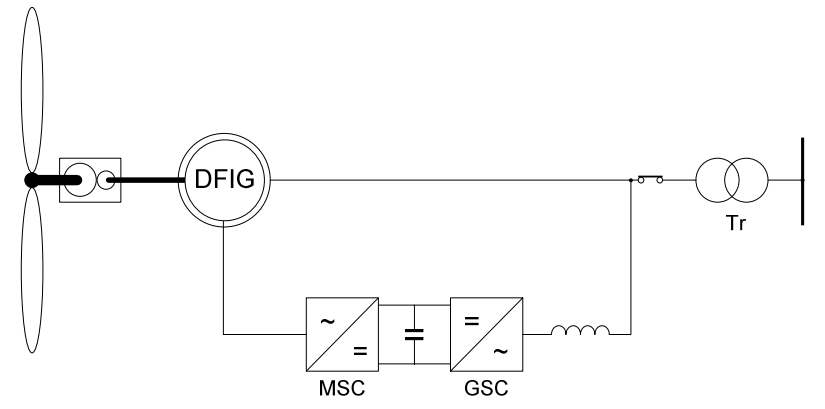

Fig. 3. Model system.

The performance of the proposed algorithm was investigated for the cases of wind speed variation, internal faults, and external faults. To simulate a turn-to-turn fault of the winding, we modeled a portion of the internal impedance of the winding as the impedance of the external terminal windings, and then shorted the divided external impedance at the instant of the fault [15]. In this simulation, the sampling rate was 64samples/cycle and an anti-aliasing lowpass RC filter with a stop-band cutoff frequency of 1920 $\mathrm{Hz}$ was used.

\subsection{Transient State}

\section{Case 1: wind speed variation}

Fig. 4 shows the results for case 1, where the wind speed changes from $10 \mathrm{~m} / \mathrm{s}$ to $15 \mathrm{~m} / \mathrm{s}$ at $50 \mathrm{~ms}$. This case simulates the time scale for a long-term comparison with other cases, because the transient of wind speed changes takes the 300 ms. Figs. 4(a)-(d) show the three-phase currents and voltages of the stator and the rotor. The solid, dotted, and dashed lines represent the A-phase, B-phase, and C-phase, respectively. The stator voltages were not changed because the stator was connected to the grid as shown in Fig. 4(a). On the other hand, the stator currents increased at $50 \mathrm{~ms}$ because of the increased wind speed, as shown in Fig. 4(b). The values of $v_{d 1}^{s}$ and $v_{d 2}^{s}$ calculated from (24) and (25) are represented in Fig. 4(e), and the values of $v_{q 1}^{s}$ and $v_{q 2}^{s}$ calculated from (26) and (27) are shown in Fig. 4(f). The solid lines represent $v_{d 1}^{s}$ and $v_{q 1}^{s}$, and the dotted lines represent $v_{d 2}^{s}$ and $v_{q 2}^{s}$. As expected, the induced voltages were nearly the same in the case of wind speed variation, because the parameters of a DFIG did not change. In Figs. 4(g) and 4(h), the errors from the D detector and the Q detector are smaller than $0.1 \%$ before and after the wind speed variation. Therefore, the trip signal was not activated, as shown in Fig. 4(i).

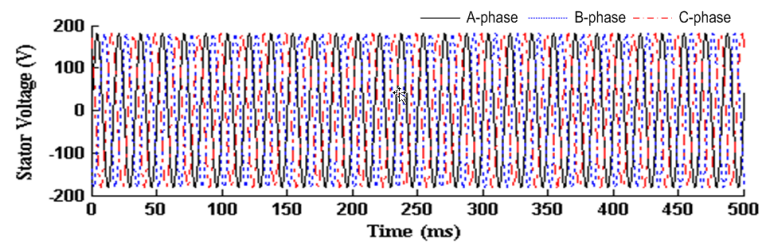

(a) Voltages in stator 


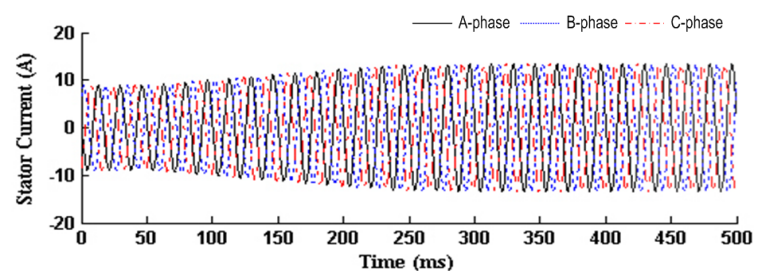

(b) Currents in stator

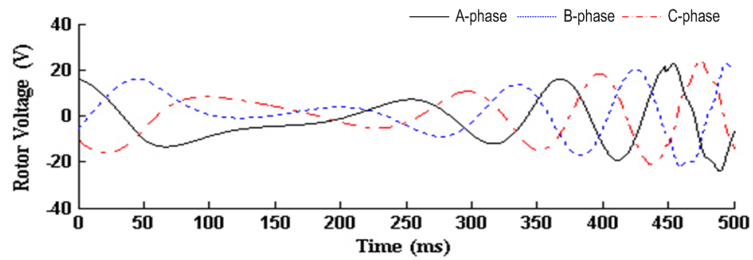

(c) Voltages in rotor

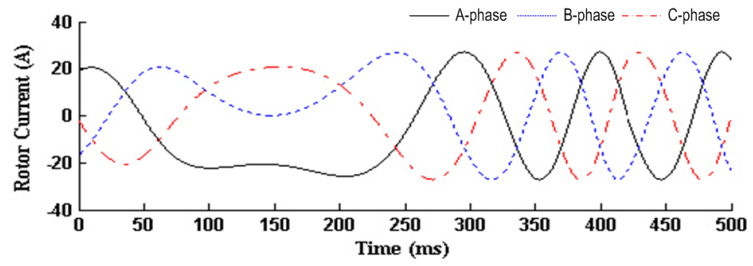

(d) Currents in rotor

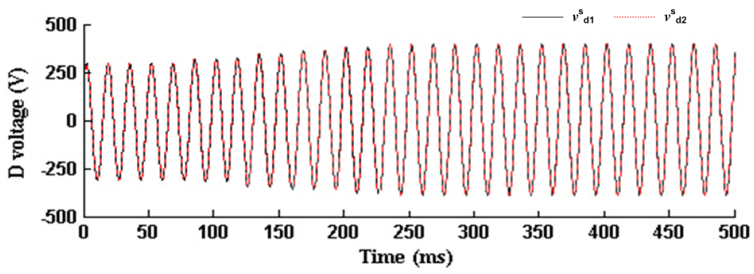

(e) Induced voltages of $L_{\mathrm{m}}$ in d-axis

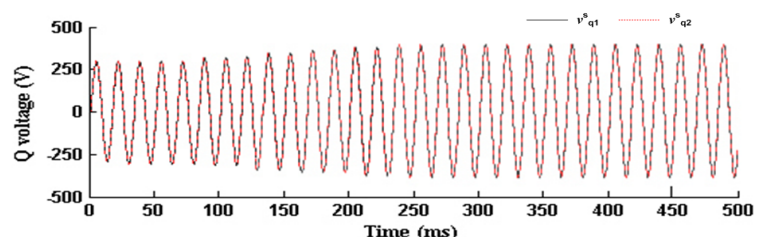

(f) Induced voltages of $L_{\mathrm{m}}$ in q-axis

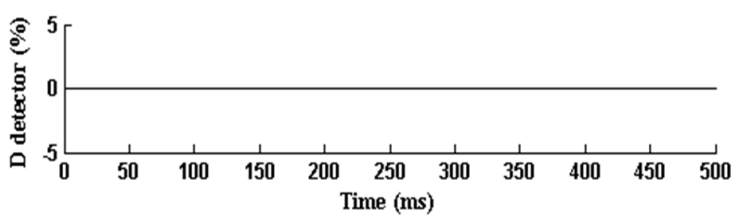

(g) D_detector

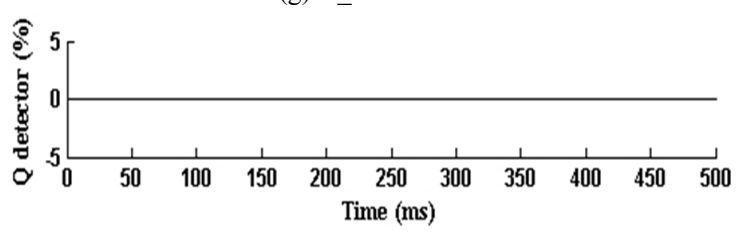

(h) Q_detector

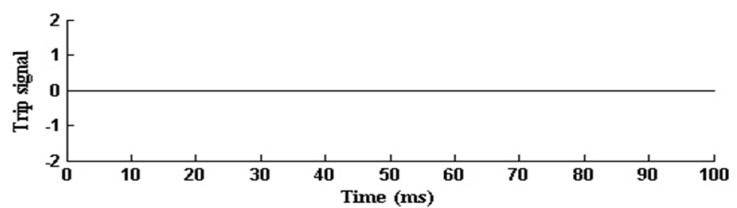

(i) Trip signal

Fig. 4. Results for case 1.

\subsection{Internal Faults}

\section{Case 2: $40 \%$ turn-to-turn fault}

Fig. 5 shows the results for case 2, where an A-phase stator winding fault occurs at $50 \mathrm{~ms}$. The stator voltages did not change because the stator is connected to the grid, as shown in Fig. 5(a). On the other hand, the stator current of

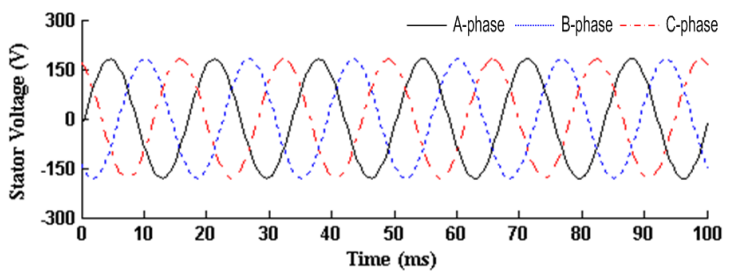

(a) Voltages in stator

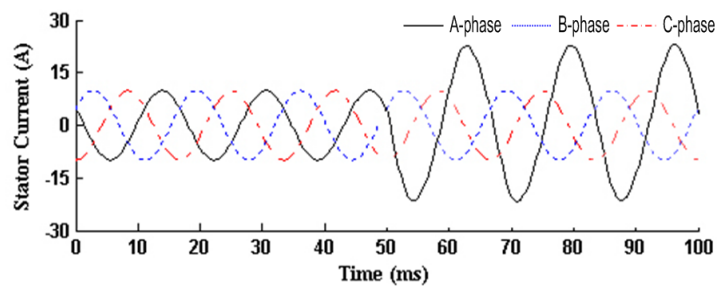

(b) Currents in stator

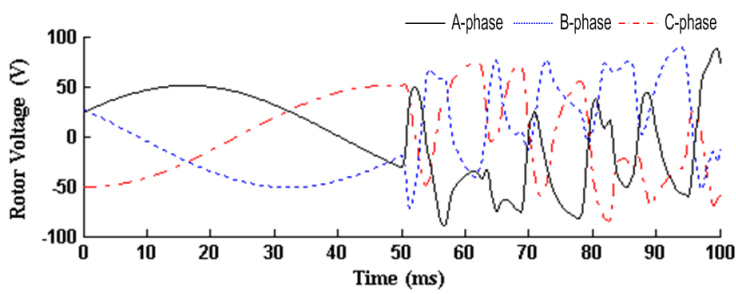

(c) Voltages in rotor

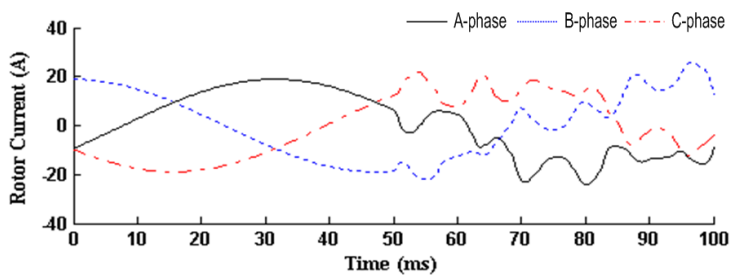

(d) Currents in rotor

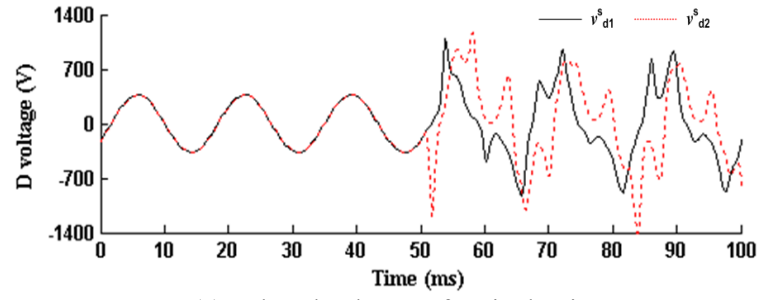

(e) Induced voltages of $L_{\mathrm{m}}$ in d-axis

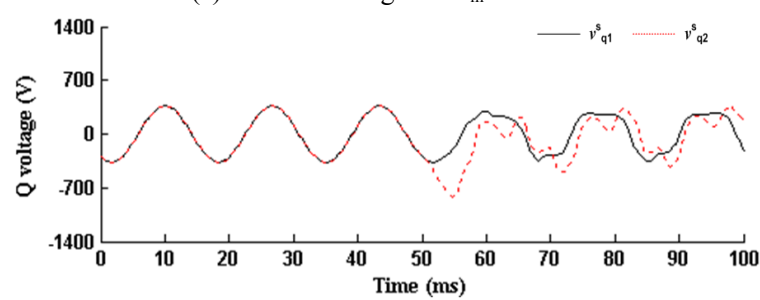

(f) Induced voltages of $L_{\mathrm{m}}$ in q-axis 


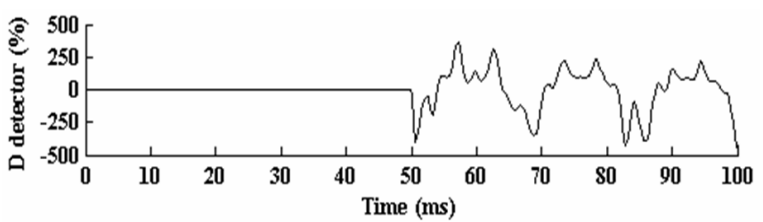

(g) D_detector

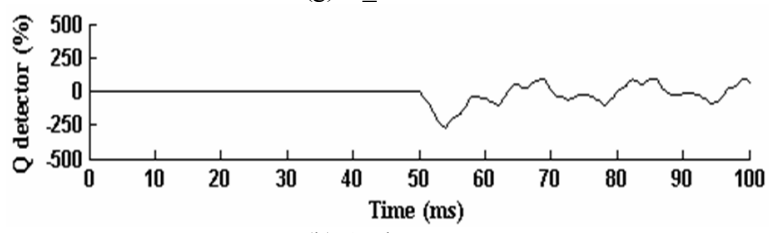

(h) Q_detector

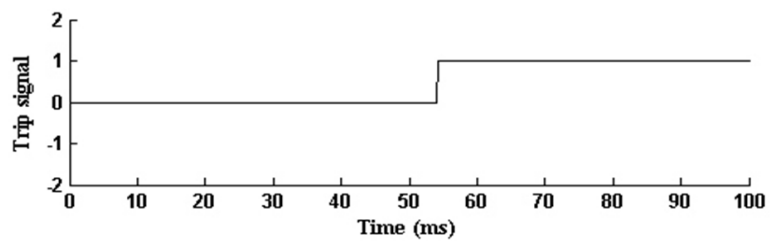

(i) Trip signal

Fig. 5. Results for case 2 .

the A-phase increased at $50 \mathrm{~ms}$ as shown in Fig. 5(b), because the impedance of the A-phase stator winding was reduced after the turn-to-turn fault. As shown in Figs. 5(e) and 5(f), the values of $v_{d 1}^{s}, v_{d 2}^{s}$, and also $v_{q 1}^{s}, v_{q 2}^{s}$ were nearly the same prior to the fault. However, after the fault, they become different due to the change of parameters in a DFIG. As shown in Figs. 5(g) and 5(h), the calculated errors from the $\mathrm{D}$ detector and $\mathrm{Q}$ detector were smaller than $0.1 \%$ before the fault, and becomes large $(-408 \%$ and $267 \%$ ) after the fault. Therefore, the trip signal was activated at $4.16 \mathrm{~ms}$ after the turn-to-turn fault, as shown in Fig. 5(i).

\section{Case 3: Line-to-line fault}

Fig. 6 represents the results for case 3, a line-to-line fault in the stator windings at $50 \mathrm{~ms}$. In Figs. 6(a) and 6(b), the A-phase and the B-phase stator voltages decreased, and the A-phase and the B-phase stator currents increased at $50 \mathrm{~ms}$ due to the line to line fault in the stator windings. In Figs. 6(e) and 6(f), the values of $v_{d 1}^{s}, v_{d 2}^{s}$ and $v_{q 1}^{s}, v_{q 2}^{s}$ were nearly same in the steady state. However, they become significantly different after the fault, due to the change of parameters in a DFIG. In Figs. 6(g) and 6(h), the calculated errors from the $\mathrm{D}$ detector and the $\mathrm{Q}$ detector have large values $(40,830 \%$ and $17,550 \%$, respectively) after the fault. Therefore, the trip signal was activated at $4.16 \mathrm{~ms}$ after the fault, as shown in Fig. 6(i).

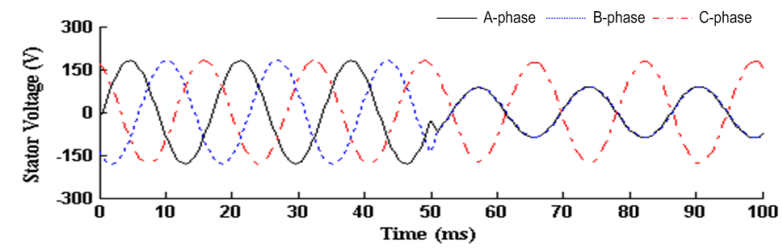

(a) Voltages in stator

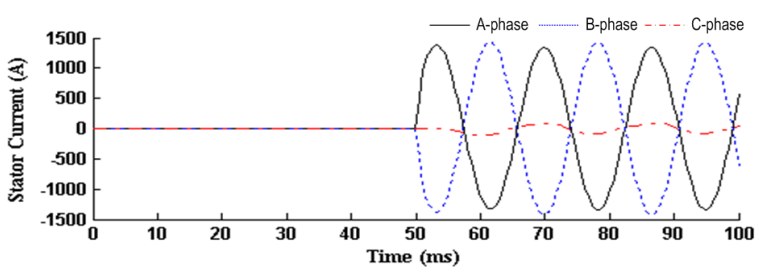

(b) Currents in stator

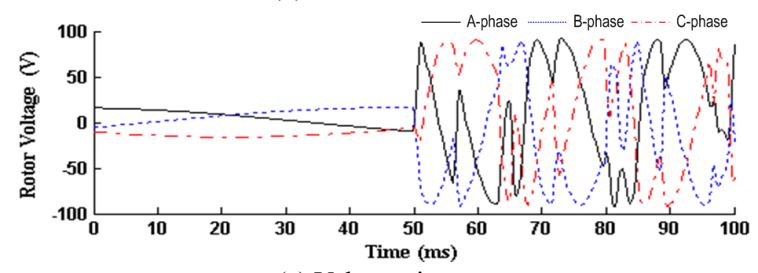

(c) Voltages in rotor

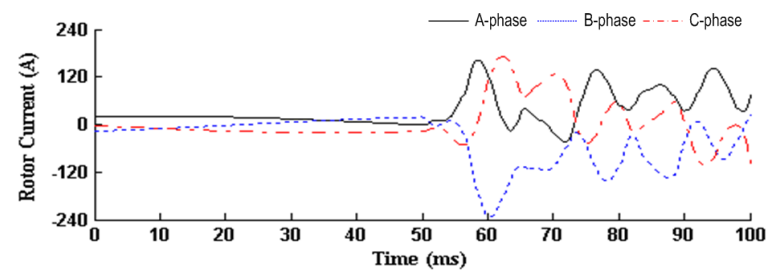

(d) Currents in rotor

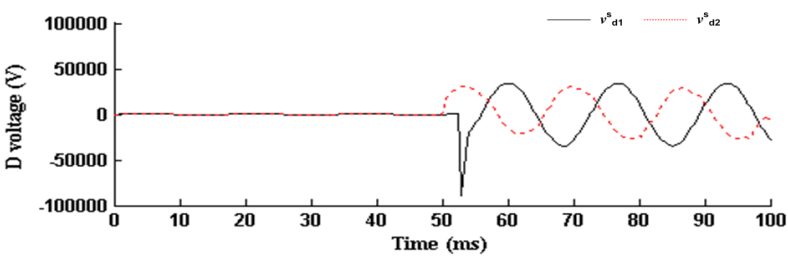

(e) Induced voltages of $L_{\mathrm{m}}$ in d-axis

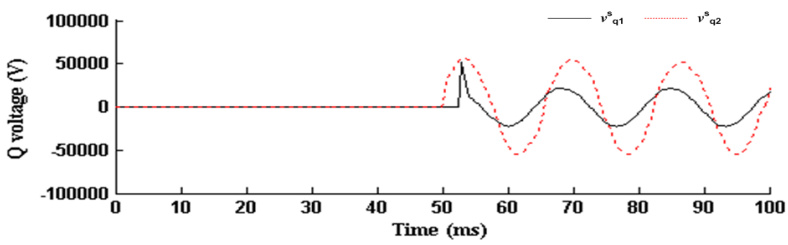

(f) Induced voltages of $L_{\mathrm{m}}$ in q-axis

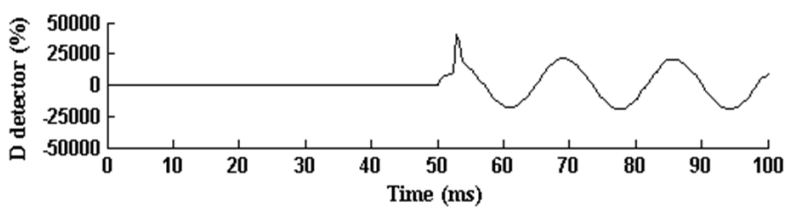

(g) D_detector

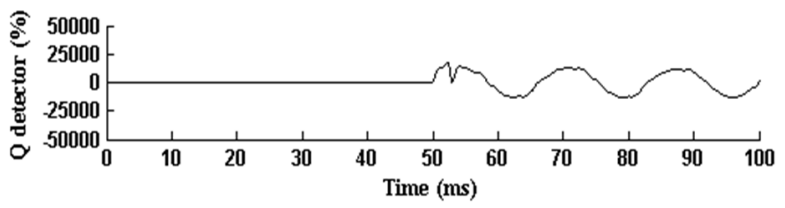

(h) Q_detector

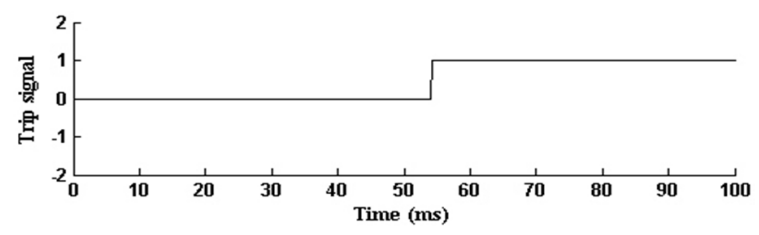

(i) Trip signal

Fig. 6. Results for case 3. 


\subsection{External Fault}

\section{Case 4: Single line-to-ground fault}

Fig. 7 represents the results of case 4, an A-phase-toground fault at $50 \mathrm{~ms}$, where the fault distance is $0.5 \mathrm{~km}$ from the circuit breaker connected to the grid. As shown in Figs. 7(a) and 7(b), the A-phase stator voltages decreased and the A-phase stator currents increased at $50 \mathrm{~ms}$ due to the external fault. As shown in Figs. 7(e) and 7(f), the values of $v_{d 1}^{s}, v_{d 2}^{s}$ and $v_{q 1}^{s}, v_{q 2}^{s}$ were nearly the same in the external fault because the parameters of a DFIG did not change. As shown in Figs. 7(g) and 7(h), the calculated

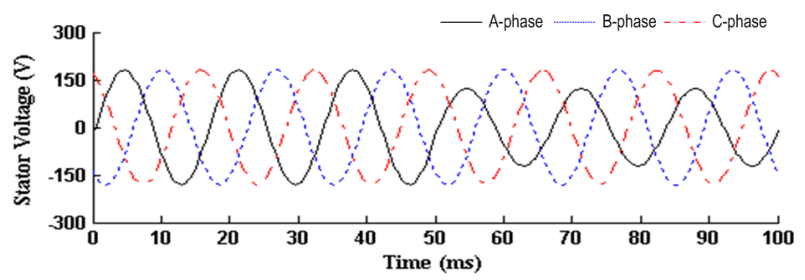

(a) Voltages in stator

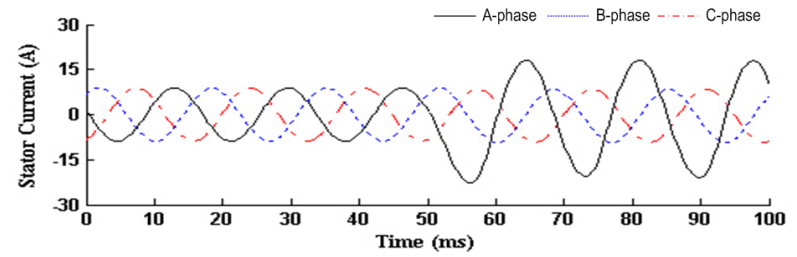

(b) Currents in stator

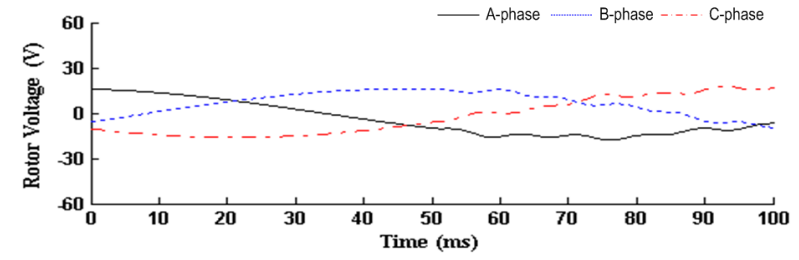

(c) Voltages in rotor

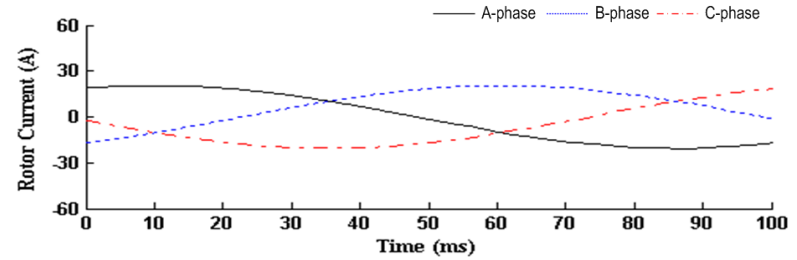

(d) Currents in rotor

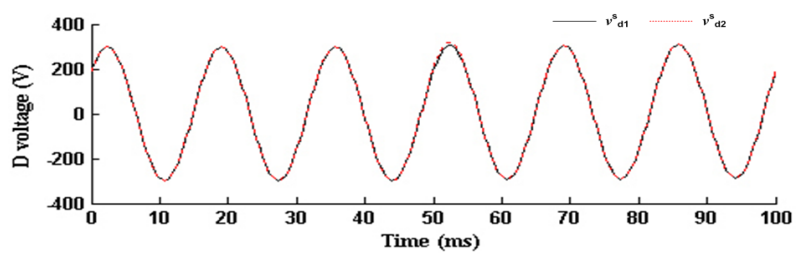

(e) Induced voltages of $L_{\mathrm{m}}$ in d-axis

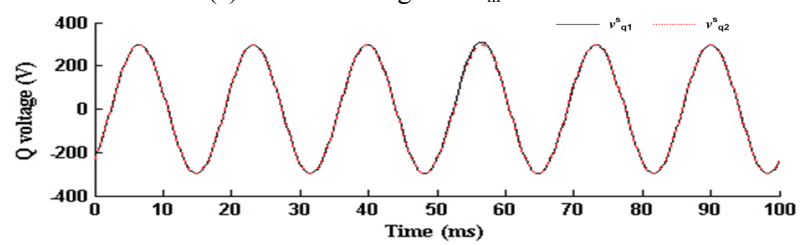

(f) Induced voltages of $L_{\mathrm{m}}$ in q-axis

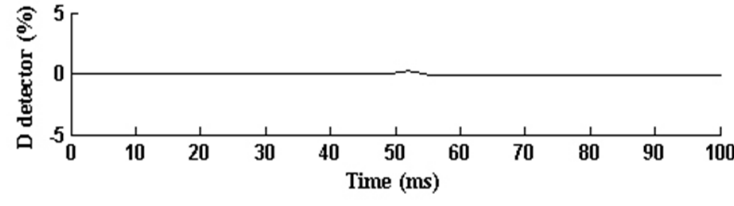

(g) D_detector

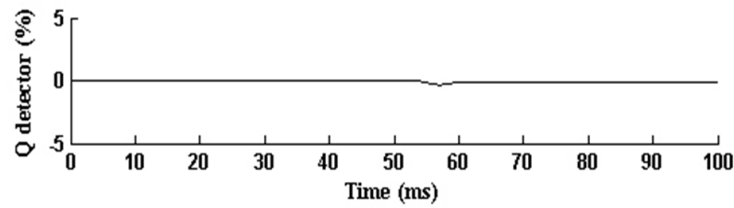

(h) Q_detector

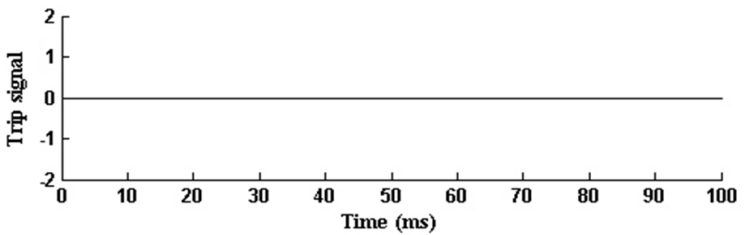

(i) Trip signal

Fig. 7. Results for case 4.

errors from the $\mathrm{D}$ detector and the $\mathrm{Q}$ detector had small values $(0.5 \%$ and $-0.54 \%)$ after the fault. Therefore, the trip signal was not activated, as shown in Fig. 7(i), because the errors were smaller than the threshold $5 \%$.

\section{Conclusion}

We proposed a protection algorithm for a DFIG based on a $d-q$ equivalent circuit in the time domain. The proposed algorithm estimates the two instantaneous induced voltages of the magnetizing inductance from the stator side and the rotor side in the $\mathrm{d}-\mathrm{q}$ equivalent circuit. If the difference between the two estimated induced voltages exceeds a threshold, the algorithm detects the internal fault.

Using a PSCAD/EMTDC simulator, we verified the performance of proposed algorithm by simulating cases for the transient state, internal faults, and an external fault. The results show that the proposed algorithm activates the trip signal within $1 / 4$ cycle after the internal faults, and does not activate for the transient state (such as wind variation) and an external fault.

The proposed algorithm can discriminate correctly the internal faults from the external faults or transient states, and can also detect the turn-to-turn faults, which cannot be detected by the conventional current differential protection system of DFIG.

\section{Acknowledgements}

This work has been supported by KESRI (2009T100100597), which is funded by MKE (Ministry of Knowledge Economy). 


\section{References}

[1] J. B. Ekayanake, L. Holdsworth and N. Jenkins, Control of Doubly Fed Induction Generator (DFIG) Wind Turbines.

[2] T. Ackermann, Wind Power in Power Systems, John Wiley \& Sons, Ltd.

[3] L. H. Hansen, L. Helle, F. Blaabjerg, E. Ritchie, S. Munk-Nielsen, H. Bindner, P. Soerensen and B. BakJensen, "Conceptual survey of Generators and Power Electronics for Wind Turbines," Risoe-R-1205(EN), Risoe National laboratory, December, 2001.

[4] Dr. Eggert and S. Franko, "Innovative Variable Speed Drive for Doubly Fed Wind Turbine Application," 2002 World Wind Energy Conference and Exhibition, July, 2002.

[5] R. Pena, J. C. Clare and G. M. Asher, "Doubly fed induction generator using back-to-back PWM converters and its application to variable-speed windenergy generation," IEE Proc.-Electr., Power Appl., Vol. 143, No. 3, pp. 231-241, May 1996.

[6] J. Yang, S. B. Lee, J. Yoo, S. Lee, Y. Oh and C. Choi, "A Stator Winding Insulation Condition Monitoring Technique for Inverter-Fed Machines," Power Electronics, IEEE Transactions on, Vol. 22, No. 5, pp. 2026-2033, Sept. 2007.

[7] V. Dinkhauser and F. W. Fuchs, "Detection of rotor turn-to-turn faults in doubly-fed induction generators in wind energy plants by means of observers," Power Electronics and Applications, 2009. EPE '09. 13th European Conference on, Sept. 2009.

[8] Generator Protection, IEEE Recommended practice for protection and coordination of industrial and commercial power systems.

[9] A. R. Bergen and V. Vittal, "Power System Analysis 2nd edition," Prentice Hall Inc., pp. 514-516, 2000.

[10] A. Siddique, G. S. Yadava and B. Singh, "A review of stator fault monitoring techniques of induction motors," Energy Conversion, IEEE Transaction on, Vol. 20, No. 1, pp. 106-114, Mar. 2005.

[11] P. C. Krause, O. Wasynczuk and S. D. sudhoff, Analysis of Electric Machinery and Drive Systems, Wiley Interscience, 2002.

[12] G. R. Slemon and A. Straughen, Electirc Machines, Addison-Wesley Publishing Company, Oct. 1982.

[13] W. Leonhard, Control of electrical drives, SpringerVerlag, $2^{\text {nd }}$ edition, 1996.

[14] L. Morel, H. Godgroid, A. Mirzaian and J. M. Kauffmann, "Doubly-fed induction machine: converter optimization and field oriented control with out position sensor," IEE Proc.-Electr., Power Appl., Vol. 145, No. 4, pp. 360-368, July, 1998.

[15] Z. Cai, A. Gao and J. Jiang, "Modeling for Interior Faults of Induction Motors and Its Simulation on EMTDC," IPST 2003 in New Orleans, USA.

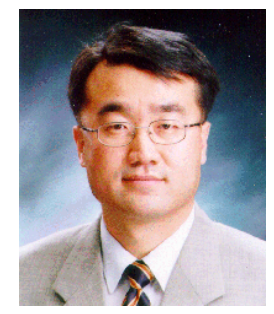

Yong-Cheol Kang received his B.S., M.S. and Ph.D. degrees from Seoul National University, Seoul, Korea, in 1991, 1993 and 1997, respectively. He is now a Professor at Chonbuk National University, Chonju, Korea. His research interest is the development of new protection systems for power systems including wind power generation using digital signal processing techniques.

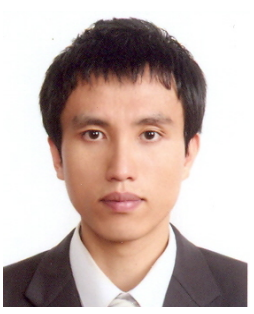

techniques.

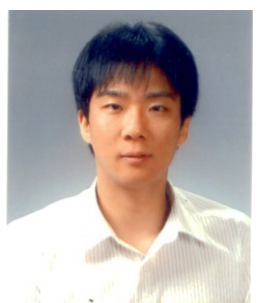

Hae-Gweon Kang received his B.S. degree from Chonbuk National University, Korea, in 2008. He is now pursuing an M.S. degree at Chonbuk National University, Chonju, Korea. His research interest is the development of new protection systems for power systems using digital signal processing

Ji-Hoon Lee received his B.S. and M.S degrees from Chonbuk National University, Korea, in 2006 and 2008, respectively. His research interest is the development of new protection systems for power systems using digital signal processing techniques. 